\title{
O JORNALÍSTICO E O LITERÁRIO NA LEITURA ESCOLAR: O USO DA CRÔNICA COMO GÊNERO MOTIVADOR PARA A FORMAÇÁO DO LEITOR
}

\author{
Karoliny Gomes Ramos
}

\begin{abstract}
Resumo
Este artigo pretende se configurar como um estudo sobre a leitura e seus meios de motivação e incentivo em sala de aula. Nesse sentido, investiga a viabilidade do uso da crônica como gênero capaz de favorecer a prática da leitura escolar e, conseqüentemente, a formação do leitor. Para tanto, faz algumas consideraçóes sobre a mesma e o gênero crônica, apresentando uma prática de leitura de crônicas desenvolvida com alunos da $2^{\text {a }}$ série do ensino médio. A realização dessa atividade teve o propósito de observar se os educandos, diante de textos inseridos no discurso jornalístico, despertaram ou ampliaram seu interesse pela leitura, de modo a se tornarem leitores críticos e socialmente participativos.

Palavras-CHaVE: crônica, leitura escolar, formação do leitor.

The journalistic and the literary in the school literature: the use of the chronicle as motivator gender for the reader's formation
\end{abstract}

\section{AbStract}

This article has the aim to be a study on reading and its means of motivation and incentive in classroom. It investigates the feasibility of using chronicle gender to encourage school reading practice and as a consequence, the formation of reader. For this some considerations are taken about reading and the chronicle gender and a development of a chronicle reading practice with second year High School students is presented. This activity had the aim to observe if the students, before the texts inserted in the journalist discourse, had awakened or augmented their interest for reading so as to become critical readers and socially participative.

KEY WORDS: chronicle, school reading, the reader's formation.

As discussóes sobre a prática de leitura em sala de aula não são novas. Ainda hoje são muitos os educadores, pesquisadores, profissionais da educação e pais que discutem o assunto a fim de buscar alternativas para superar as dificuldades de seu desenvolvimento no ambiente escolar e estimular a formação de novos leitores. Sáo inúmeros os estudos e as reflexóes

Professora de Língua Portuguesa da Rede Estadual de Ensino de Goiás. E-mail: karolgramos@hotmail.com. 
a esse respeito, porém, nada que tenha chegado à exaustão ou a conclusóes definitivas. Apesar das opinióes serem diversas, muitas são coincidentes sobre aquilo que se adota como prática e que deveria ser modificado, abandonado ou implementado, seja no cotidiano familiar, escolar, social e cultural das pessoas, para o favorecimento da formação e efetivação de um público leitor que consiga realizar a leitura como prática de construção de sentidos no texto. Assim sendo, tomo a liberdade de também me "aventurar” nesse debate e fazer algumas considerações. É certo que as reflexões que aqui serão realizadas já foram feitas por outros estudiosos, entretanto, discutir o tema é sempre uma necessidade, principalmente entre aqueles que estão diretamente envolvidos com a formação do leitor.

Inicialmente, a denominação leitura escolar vem aqui somente como referência ao objeto de estudo. Sua prática não se modifica em decorrência do ambiente, ou, ao menos, não deveria se modificar. Realizada na escola, em casa, no banco da praça, na biblioteca, no ônibus ou em qualquer outro lugar em que o leitor se sinta à vontade, continuará sendo leitura. E é justamente aí que reside um de seus problemas: durante muito tempo, e é possível que até hoje, os textos utilizados em sala de aula eram vistos como algo diferenciado daquilo que o indivíduo poderia ler em outros momentos, ou seja, na escola a leitura tinha outros fins, quase sempre didáticos.

O que se percebe é que ainda hoje o livro é utilizado nas escolas como suporte pedagógico; instituiu-se que ler é importante, o que não deixa de ser verdade, mas, ao que parece, o que se faz com a leitura tornou-se mais relevante. Os fins realmente esperados são os relatórios, as fichas, as provas e tudo mais que se possa utilizar como recurso didático e, assim, os textos em nada, ou muito pouco, fazem sentido para a vida do aluno.

Se a função da escola é a formação de leitores competentes e capazes de se transformarem, gradativamente, pela prática de leitura, em indivíduos críticos e aptos a enfrentarem desafios, sua missão será a de propiciar meios para o desenvolvimento das potencialidades intelectuais dos alunos. Somente através de uma prática que lhes permita a possibilidade de preencher os espaços vazios de um texto com suas experiências, a multiplicação de interpretaçóes que ocorrem a partir do encontro leitor-livro e a convergência de significados de outras leituras, é que se poderá desenvolver verdadeiramente a habilidade de leitura, proporcionando um sentido à realidade que circunda o leitor e provocando sua reflexão, compreensão e ação transformadora sobre os fatos da sociedade. 
A leitura mecânica, desprovida de atitude crítica e que permite apenas a recepção de informaçóes, torna o leitor um aprendiz passivo e mero reprodutor de argumentos, açóes que, para ele, não responderão às suas necessidades, além de colocá-lo em situação de risco de alienação, já que pode ficar preso às amarras do livro, sem a possibilidade de expandir o conhecimento. O desenvolvimento da capacidade da leitura crítica que provoca as inferências, as interpretaçóes e a construção de significados torna-se imprescindível, pois, por esse processo, o leitor se tornará competente para aceitar ou rejeitar aquilo que a obra tem a lhe oferecer.

A função da escola que pode se configurar como prática eficiente é a incorporação, paulatina, ao cotidiano do aluno, de novos textos que ampliem sua capacidade e seu interesse pela leitura; textos que superem as necessidades e expectativas e enriquecem as experiências do leitor com a obra e com a cultura, em conseqüência. Para isso, torna-se importante observar os que são lidos no cotidiano da sociedade e pensar como eles podem ser levados para a sala de aula, investindo mais em atividades que estimulem uma atitude de reflexáo constante, favorecendo o desenvolvimento das potencialidades intelectuais dos educandos.

Para o sucesso dessa ação é necessário, no entanto, que os professores se libertem de certos dogmas ou posiçóes cristalizadas, se desvinculem de concepçóes ultrapassadas e utilizem sua liberdade para criar, escolher e alterar as atividades que julgarem convenientes para cada leitura. Essa seleção deve ser realizada de acordo com a necessidade e com a confiança em seu poder de decisão, pautando-se no conhecimento que tem de seus alunos e de seus níveis de leitura e na eficiência da atividade para o texto que propóem trabalhar.

A decisão pelo uso ou não de determinadas atividades deve ser tomada a partir da observação do professor sobre sua necessidade. Usá-las apenas como recurso obrigatório poderá surtir efeitos contrários aos desejados, como o afastamento do leitor em relaçáo ao livro, uma vez que, como qualquer outro ato que se pratica por obrigação, torna-se enfadonho, chato e cansativo. Obrigação, imposição e outras práticas autoritárias não estimulam o aluno, não o levam a reconhecer a importância de sua formação como leitor, já que são atividades opostas aos seus interesses.

Nunes (1996) diz que a leitura obrigatória e, mais especificamente, a literária, pode ser constrangedora, e, ainda segundo o autor, os textos dos quais nos aproximamos de modo livre, seja por certa afinidade ou pelo 


\section{Revista Solta a Voz, v. 19, n. 1}

interesse que despertam, são os que contribuem para nossa experiência. Sendo assim, a eficiência da prática de leitura vai depender do modo como o leitor se aproxima do livro, melhor quando esta se dá por vontade própria. Sozinho, o indivíduo nem sempre vai procurar pelos livros, assim, o estímulo rende melhores resultados do que a imposição. Cabe, então, ao professor, utilizando os meios que julgar mais eficientes, investigar o que desperta a atenção do aluno e utilizar as informaçóes obtidas como meio de motivação. Bamberger (2005, p. 31) afirma que "o que leva o jovem leitor a ler não é o reconhecimento da importância da leitura, e sim as várias motivaçóes e interesses que correspondem à sua personalidade e ao seu desenvolvimento intelectual".

Nesse contexto, a leitura da crônica, um gênero acessível ao leitor comum, pois está todos os dias nos jornais, surge como uma alternativa para contribuir para a formação e o estímulo de jovens leitores, principalmente pelas características que apresenta, tanto no que diz respeito à estrutura quanto ao conteúdo. Pode servir a agradáveis leituras despropositadas, oferecendo momentos de deleite e de descontração, ou ser utilizada como instrumento de análise de comportamentos e de situaçóes diversas. $\mathrm{Na}$ introdução ao volume 1 da coleção "Para gostar de ler" (Andrade et al., 2001), os autores Carlos Drummond de Andrade, Fernando Sabino, Paulo Mendes de Campos e Rubem Braga afirmam que a obra não tem intenção de ensinar, seu único objetivo é a descoberta de outros mundos pela leitura, e finalizam dizendo que as crônicas são apenas o começo, que há muitas coisas a descobrir através da leitura de outros livros.

A partir dessas considerações, percebe-se que a crônica não carrega o objetivo didatizante, mas pode formar leitores, uma vez que impulsiona a prática da leitura por meio de seus textos leves e, na maioria das vezes, divertidos. Entretanto, para verificar a viabilidade de seu uso e discutir com propriedade as questôes referentes a esse gênero não basta levá-la para a sala de aula e observar como os alunos-leitores se comportam diante desse tipo de texto. É necessário conhecer o gênero e suas peculiaridades.

A crônica é um gênero que fixa seus limites entre a realidade palpável e a imaginação. Seu autor - o cronista - busca nos acontecimentos cotidianos o conteúdo para seu texto, mas não se prende apenas à narração de um fato. Na verdade, ele capta o que passa diante de nós e que deixamos escapar. Pelo conteúdo, aproxima-se do leitor e o envolve a ponto de transformar uma situação trivial em um fato que explora a sua capacidade 
de reflexão e de análise crítica. Desperta-lhe, também, a sensibilidade e a emoção, tocando os sentimentos humanos e eternizando momentos que não passariam de circunstâncias efêmeras se não fosse seu trabalho sensível de percebê-los em meio ao turbilhão de informaçóes e acontecimentos que, muitas vezes, passam despercebidos.

Texto de caráter híbrido, que na atualidade mistura jornalismo e literatura, podendo fazer a investigaçáo de um passado remoto ou se envolver com o presente, a crônica está diretamente ligada ao tempo, como o próprio radical grego cronos indica, e surgiu de um mito da antiguidade clássica. Entretanto, muitos, ainda hoje, não conseguem definir especificamente o que é esse texto de natureza ambígua. Se verificarmos o que alguns escritores, estudiosos e críticos escrevem a respeito do gênero, perceberemos que cada um procura a melhor maneira para definir o que ele é, mas nem sempre chegam a uma explicação objetiva; muitas vezes, o melhor caminho encontrado para garantir o entendimento é o uso de metáforas.

A dificuldade em reconhecer os limites da crônica se deve às características peculiares que esta adquiriu em nosso país, sendo a primeira delas o fato de os cronistas tomarem como ponto de partida para sua construção a realidade palpável, mas dando contornos ficcionais ao texto, que não tem a obrigação de ser fidedigno à realidade. De acordo com Melo (2005, p. 147), a crônica é "um relato poético do real", pois sua função não é a de reconstituir fatos divulgados no jornal, mas a de descortinar seus significados e mostrá-los por meio de um olhar diferente daquele puramente jornalístico. É nesse momento que entra o trabalho do cronista de utilizar os recursos literários para construir o texto. Para Bender e Laurito (1996), tudo que a elaboração literária permite pode ser usado na crônica, desde figuras de linguagem a recursos gramaticais, para a composição de um texto aparentemente simples e fácil de ser elaborado, mas que, no entanto, depende do talento de seu escritor para que haja esse efeito despretensioso que mais parece uma conversa com um amigo.

Além de permear um duplo caminho, o do jornalismo e o da literatura, outra razão para que não apresente limites bem definidos é que os cronistas, gozando da liberdade que têm para escrever, adotam estilos particulares e fazem uso, não raro, de outros gêneros literários na criação de seus textos. Nesse caso, pode-se falar da crônica como gênero flexível, que ora se aproxima de um ensaio, ora de um conto, por exemplo. 


\section{Revista Solta a Voz, v. 19, n. 1}

Tais peculiaridades mostram que a crônica, ao vir para o Brasil e encontrar nossos escritores, não só se adaptou bem, como adquiriu aspectos que são próprios da literatura e do jornalismo do país. Galvani (2005, p. 34) se atreve a dizer que "a língua portuguesa vê a crônica, desde seus primórdios, como o campo do invento e da experiência, da aventura e da valentia, o legítimo lugar onde a palavra voa, desenvolta, solta no espaço do imaginário". Afirma ainda que "dificilmente encontraremos, em outras terras, um cronista na acabada versão brasileira" (idem, p. 41). Esse estudioso da crônica não é o único que a vê como produto típico do Brasil. Candido (1980) conclui que, pela receptividade e maneira como aqui foi desenvolvida, se poderia dizer que é um gênero brasileiro. Cony (1998) parece compartilhar a mesma idéia ao afirmar, em entrevista a César Fraga, que não existe equivalente em outros países à produzida aqui.

Apesar de se aclimatar tão bem ao nosso país, a crônica é, ainda hoje, vítima de preconceitos por apresentar um conteúdo de aparente simplicidade e efemeridade. Tal conclusão pode ser entendida como preconceito porque a crônica parece ser mesmo simples, já que o cronista procura estabelecer no texto uma certa proximidade com o tom coloquial da conversa entre amigos. Entretanto, para obter esse efeito, necessita de um trabalho de elaboração cuidadosa do texto. Além disso, pode ser efêmera, pois, como típica do meio jornalístico, corre o risco de ter a duração breve de um jornal, porém, atualmente, já são muitas as produções que ganharam espaço nas páginas dos livros. Como afirma Cony (1998), é um gênero temporal, mas não pode ser considerado um defunto; apesar de ser um texto datado, é capaz de resistir ao tempo e sobreviver não só ao jornal, pois, apesar de ser um produto típico do jornalismo brasileiro, não é exclusividade desse meio.

Candido (1980) afirma que a crônica é um gênero menor, porém, segundo ele, não se trata de algo ruim, porque, sem a grandiosidade atribuída a outros gêneros, está mais perto dos leitores comuns e pode servir de caminho para a vida e para a literatura. Afirma, também, que através dos seus assuntos, "do ar de coisa sem necessidade", pode levar o leitor a um despertar para a reflexão e para o uso da sensibilidade perante as situaçóes com as quais entra em contato (idem, p. 5). Ainda de acordo com esse crítico, seus traços constitutivos são um veículo privilegiado para mostrar de modo persuasivo muitas coisas que, divertindo, atraem, inspiram e fazem amadurecer a nossa visão de mundo. 
Nas palavras do autor, nesse mesmo estudo, não há uma desvalorização da crônica, mas uma identificação de sua singularidade, dos aspectos que a constituem como literatura ao "rés-do-chão", para usar aqui uma expressão do próprio crítico, próxima do leitor comum, daquele do cotidiano, que abre os jornais para tomar conhecimento dos fatos que ocorrem na sociedade, mas que também deseja algo além do simples relato, e procura nesse gênero um olhar diferente sobre a realidade, capaz de fazê-lo compreender melhor determinadas situaçóes de sua própria vida.

Se nos compêndios de literatura a crônica não recebeu lugar de destaque, em contrapartida, conseguiu a aceitação de um público cada vez maior, que se identifica com as situações e emoçóes que são registradas pelos cronistas, reconhecidos pelo seu trabalho e que alcançaram alto nível de popularidade. Se ela é feita para "homens menores", "míseros mortais", como afirmam Bender e Laurito (1993, p. 45), não significa que seja um texto com qualidade inferior, e sim um texto que fala de perto ao ser humano e desperta nele a humanidade que, por diversas circunstâncias, fica esquecida. Não é necessário construir uma obra "pesada”, complexa, para se obter seriedade. Segundo Candido (1980), na leveza pode-se também falar de coisas sérias, e a crônica vem fazer justamente isso. $\mathrm{Na}$ sua quase simplicidade cotidiana, chama a atenção sobre questóes sérias e pede a observação mais atenta para a vida e a humanidade.

A crônica foi escolhida como gênero norteador deste trabalho por apresentar características singulares capazes de favorecer, como já afirmado anteriormente, a sua aproximação com diferentes tipos de leitores e, também, por permitir-lhes uma investigação acerca de sua construção, de seu funcionamento e do sentido que produz. Os leitores podem contar com inúmeras possibilidades de exploração, já que é possível apontar significados e relaçóes para os textos, entender os contextos, dialogar com outras produçóes e até desenvolver a sensibilidade para compreender a experiência do artista.

A prática de leitura foi desenvolvida no Colégio Estadual Senador Theotônio Villela, no município de Trindade, com 31 alunos, com média de 14 a 16 anos de idade, da segunda série do ensino médio do turno matutino. Para sua realização, foram escolhidas dez crônicas publicadas no jornal O Popular nos anos 2005 e 2006.

As crônicas selecionadas foram lidas em sala de aula, discutidas e exploradas por meio de atividades variadas. Após cada leitura, o pedido era 


\section{Revista Solta a Voz, v. 19, n. 1}

para que se manifestassem a seu respeito e expressassem a opinião sobre ela, a fim de verificar como tinha sido a compreensão do texto. As dúvidas que surgiam eram esclarecidas por mim e por outros alunos, durante as discussóes feitas após a leitura. Diante do desconhecimento de alguns assuntos e acontecimentos, tais crônicas serviram aos leitores náo apenas como meio de reflexão e observaçáo de situaçóes que poderiam passar despercebidas, mas também como meio de informação.

Feitas as discussóes iniciais, para cada uma foram propostas atividades diferenciadas para a continuação do trabalho. É importante salientar que as práticas eram um meio utilizado para verificar os níveis de leitura, pois mediante elas pode-se analisar a relação do leitor com o texto com o qual está em contato e, por esse motivo, eram diferentes em cada leitura. Também por isso, as aulas não se restringiram apenas à execução das atividades propostas: a cada momento surgiam novas possibilidades para a exploração do texto, proporcionadas pela relação que se estabelecia entre os leitores e a crônica lida naquele instante. Desse modo, sua utilização não foi pretexto para a aplicação e fixação de conceitos ou conteúdos; ao contrário, a intenção de seu uso era a aproximação entre leitor e texto e, conseqüentemente, a motivação para a prática de leitura.

A seguir, como exemplificação do trabalho em sala, apresento uma prática desenvolvida com duas crônicas.

\section{“ATENDIMENTO VIP” E “ATENDIMENTO PERSONALIZADo”}

As crônicas "Atendimento vip" (Ferreira, 2005b) e "Atendimento personalizado" (Ferreira, 2005a) foram lidas em seqüência porque abordam práticas semelhantes de atendimento ao público, o que propiciou a reflexão sobre a motivação e a intencionalidade de determinadas ações em atividades relacionadas ao comércio e à prestação de serviços.

Após a leitura dos textos, foi pedido, em relação ao primeiro, em que um médico exagera na atenção dispensada a um paciente, que relatassem o motivo das açóes narradas, e, a partir de entáo, discutissem a real finalidade deste tipo de atendimento. Pelas situaçóes ironizadas, os alunos-leitores perceberam que o doutor citado não recebia, há muito tempo, pacientes em seu consultório e, com a chegada de um, dispensou especial atenção, objetivando excelência no atendimento e satisfaçáo para o paciente a fim de que ele voltasse outras vezes. $\mathrm{O}$ exagero da personagem fez com que a consulta se 
transformasse em uma cena cômica de exageros e adulação. Tanto na crônica, que relata um acontecimento ficcional, quanto na realidade, tal tipo de atendimento existe visando atrair clientes interessados em um tratamento especial, principalmente aqueles que detêm melhores condiçóes econômicas.

Em relação à leitura do segundo texto, foi proposta uma reflexão com a intenção de levar os alunos a entender e comentar se havia nele alguma crítica e qual seria ela. Lendo atentamente a crônica, verificou-se que o substantivo "pessoa", que tanto pode ser classificado como simples ou próprio, dá início aos problemas na loja que dispensa um tratamento personalizado aos seus clientes. Desejoso de comprar uma escova de dentes, um senhor, atraído por uma propaganda, chega ao estabelecimento esperando um atendimento diferenciado, e como seu sobrenome é Silva Pessoa, o atendente, para conferir-lhe personalização, refere-se a ele como "Pessoa". Nesse momento inicia-se, assim como em "Atendimento vip", uma cena cômica, com uma discussão em torno dos significados que os sobrenomes podem evocar e as relaçóes que podem estabelecer. Um estado de confusão é instaurado na situação narrada, ainda mais quando o cliente pede uma escova que sirva adequadamente às suas necessidades de escovação e não encontra o que precisa. Nesse instante, o atendimento personalizado acaba se tornando um fiasco, causando irritação tanto no vendedor quanto no comprador.

O cronista, ao questionar a respeito do real sentido de um atendimento personalizado, cria, com humor, uma narrativa que ironiza o quanto essa prática pode se tornar problemática, assim como também o chamado tratamento vip, que pode ainda suscitar a idéia de discriminação, já que se trata de uma prática diferenciada voltada apenas para algumas pessoas.

Nos relatos dos leitores, tais atendimentos são meios de atrair clientes, muitos deles presos a futilidades e desejosos em receber a atenção que o alto poder aquisitivo pode financiar. Não houve como deixar fora da discussão os vários exemplos que surgiram desse tipo de prática evidenciada com humor pela crônica, o que propiciou uma reflexão a respeito do assunto e, também, do efeito que as propagandas produzem nos indivíduos, persuadindo-os nas suas escolhas, já que em "Atendimento personalizado" o interesse pela personalização no atendimento é motivado por uma propaganda.

Uma constatação feita sobre a leitura dessas crônicas diz respeito ao fator responsável por despertar o prazer dessa leitura. Pelos comentários dos alunos após lerem os textos antes mesmo de apresentar-lhes as ativida- 


\section{Revista Solta a Voz, v. 19, n. 1}

des, tal gosto não foi provocado simplesmente pelo tema, e sim pela maneira como foi desenvolvido, em uma narrativa cômica, que retrata cenas do cotidiano, porém em circunstâncias ridicularizadas e com um tom mais exagerado. Isso faz pensar sobre o que provoca o interesse pelo texto. Nem sempre o assunto apenas, mesmo que relevante para o leitor, é o atrativo para iniciar, continuar ou gostar da leitura. A maneira como o texto é construído, com atenção, por exemplo, para o uso de recursos de linguagem, pode favorecer uma leitura mais prazerosa.

Mesmo se tratando de um trabalho em que predomina a análise qualitativa das informaçóes, é possível afirmar, a partir da observação desses e de outros relatos, que as crônicas exerceram influência nos atos de leitura de aproximadamente $77 \%$ dos alunos. Pode-se afirmar, ainda, que tal influência ocorreu devido aos aspectos peculiares a esse gênero, como, por exemplo, o fato de serem textos que, por registrarem o circunstancial, chamam a atenção para situaçóes que circundam a sua realidade, e que muitas vezes até ignoram. Também são consideradas como textos que informam, pois muitos dos assuntos apresentados não eram anteriormente conhecidos, e, por isso, permitem também a reflexão e até a tomada de posição. Outro aspecto diz respeito à sua extensão que, por ser geralmente pequena, favorece leituras rápidas, atendendo à pressa que muitos deles apresentam.

É importante citar que a exploraçáo dos recursos literários pelo cronista na composição do texto pode contribuir para despertar a atenção dos leitores. $\mathrm{O}$ uso de figuras de linguagem, a interpolação de outros gêneros à crônica - como a poesia que esteve presente em algumas das lidas em sala -, a criaçáo de efeitos de humor para divertir o leitor ou de dramaticidade para comovê-lo, podem garantir mais beleza e leveza, estabelecer uma proximidade com o leitor e, conseqüentemente, favorecer o gosto pela leitura.

Outra observação importante a fazer é que, depois de conhecerem as crônicas utilizadas neste trabalho, alguns alunos têm levado outras para a sala de aula, para compartilharem a leitura com a turma; alguns também perguntam se seráo lidos novos textos do gênero. Observando esse comportamento dos alunos, é possível dizer que esta é uma maneira dos leitores pedirem que novos textos cheguem até eles e um indicador de que houve favorecimento à prática de leitura.

A partir do relato de experiências com a leitura de crônicas, dos comentários feitos ao longo das aulas a respeito dos textos e da observação da relação leitor-texto, pode-se fazer algumas consideraçóes sobre a prática 
de leitura em sala de aula. Primeiramente, é importante afirmar que, evidentemente, nem todos os alunos atingiram os objetivos esperados com este trabalho, como a ampliação do interesse pela leitura e a formação da capacidade crítica, já que os textos literários atuam de diferentes formas sobre cada leitor.

No entanto, foi possível perceber, pelos comentários após a leitura, pela análise das atividades que realizaram e pelos números percentuais obtidos através dos relatos, que os textos incentivaram um número considerável de alunos para a prática de ler. Muitos deles comentaram que antes desse trabalho não haviam tido qualquer contato com crônicas, alguns nem sabiam que tipo de texto era esse, e hoje, quando abrem o jornal, já procuram por elas, ávidos por encontrarem experiências, confissóes, humor ou, simplesmente, uma narrativa sobre acontecimentos simples, mas que podem oferecer-lhes algo.

A crônica, na aparente simplicidade de sua linguagem, tratando do circunstancial, que pode passar despercebido aos olhos de muitos, chama a atenção do leitor, a ponto de levá-lo a refletir sobre a vida, sem que para isso traga em seu projeto uma intenção moralizadora. $\mathrm{Na}$ sala de aula, a leitura desse gênero se mostra viável porque pode "proporcionar ao leitor a convivência íntima com a palavra” (Cruvinel, 2004, p. 81), despertar a sensibilidade, divertir, propiciar a reflexão ou instigar a curiosidade que o levará à busca por novos textos que saciem a sede motivada pela sua leitura.

A experiência relatada, apesar de não ser novidade, constituiu-se em uma proposta interessante para o trabalho, pois não teve a pretensão de se mostrar como o meio mais eficaz para o desenvolvimento da prática de leitura, e sim procurou demonstrar que a prática de leitura de textos em uma linguagem mais acessível, por isso não menos elaborada, com assuntos triviais, cotidianos, pode ser um modo viável de proporcionar o acesso do jovem leitor à leitura. Além do mais, tal experiência pode ser desenvolvida com outros leitores, desde que respeitadas suas peculiaridades, e pode servir como ponto de partida para a aplicaçáo de outras propostas e utilização de outros gêneros textuais, que serão necessários a partir do momento em que se tornar efetiva a leitura das crônicas, já que elas podem despertar o interesse por assuntos diversos, assim como para a leitura de outros gêneros literários.

Diante da situação exposta, é necessário fazer uma observação: as práticas de incentivo à leitura adotadas em sala de aula devem patrocinar uma 
aproximação livre entre leitor e livro, e a liberdade só existe quando se respeita o gosto do leitor e o seu tempo de aprendizado. A sala de aula é um ambiente heterogêneo, cada um que está ali tem personalidade diferente, traz consigo saberes diferenciados e influências externas distintas que interferem em sua relação com o aprendizado. Imposição não pode ser o caminho seguido, o exemplo ainda é uma das melhores formas de incentivo. $O$ professor que é realmente leitor tem a possibilidade de obter melhores resultados do que aquele que simplesmente aposta na reproduçáo de metodologias de outros profissionais somente porque foram eficazes em alguns contextos.

A leitura não se encerra no banco da escola. Por toda a vida ela acompanha o ser humano, servindo-lhe como fonte de conhecimento e de prazer, com um intenso poder de sedução: ela transporta o leitor do mundo real para um outro distinto e, quando volta, a realidade parece modificada, mas quem mudou foi o sujeito-leitor. E esse movimento é necessário para a evolução do ser humano.

\section{REFERÊNCIAS}

ANDRADE, C. D. de et al. Para gostar de ler. 10. ed. São Paulo: Ática, 1987. v. 1.

BAMBERGER, R. Como Incentivar o Hábito da Leitura. 7. ed. São Paulo: Ática/Unesco, 2005. 109p.

BENDER, F.; LAURITO, I. Crônica: história, teoria e prática. São Paulo: Scipione, 1993. 102p.

CANDIDO, A. A vida ao rés-do-chão. In: ANDRADE, C. D. de et al. Para gostar de ler. Edição didática. São Paulo: Ática, 1980. v. 5.

CONY, C. H. A crônica como gênero e como antijornalismo. Folha de São Paulo, São Paulo, 16 de outubro de 1998. Disponível em: <http://www. saa.com.br/quadro/ponto/cronica.htm>. Acesso em: 2 nov. 2005.

CRUVINEL, M. de F. "Cronicamente” viável: o factual e o ficcional para a formação de leitores. Revista Solta a Voz, Goiânia: Cepae - UFG, v. 15, n. 1, p. 72-83, jan./jun. 2004.

FERREIRA, C. C. Atendimento personalizado. O Popular, Goiânia, 20 mai. 2005a. Magazine, p. 8. 
FERREIRA, C. C. Atendimento vip. O Popular, Goiânia, 28 ago 2005 b. Magazine, p. 6.

GALVANI, W. Crônica: o vôo da palavra. Porto Alegre: Mediação, 2005. 120p.

MELO, J. M. de. A crônica. In: CASTRO, G. de; GALENO, A. (Orgs.). Jornalismo e literatura: a sedução da palavra. 2. ed. São Paulo: Escrituras, 2005. p. 139-154.

NUNES, B. Ética e leitura. Leitura: Teoria e Prática, Porto Alegre, ano 15, n. 27, junho 1996.

Recebido em: 15 jun. 2007 Aceito em: 15 nov. 2007 